\title{
A história da evolução do conceito físico de energia como subsídio para o seu ensino e aprendizagem - parte II $^{+*}$
}

Luciano Carvalhais Gomes ${ }^{1}$

Departamento de Física - UEM

Maringá - PR

\section{Resumo}

Este artigo tem como objetivo mostrar os aspectos essenciais do desenvolvimento do conceito físico de energia, para subsidiar a escolha dos professores quanto à melhor maneira de compreender e ensinar esse conceito, e está dividido em duas partes. Na primeira, mostramos algumas contribuições de Thomas Young, Johann Bernoulli, Galileu Galilei, René Descartes e Leibniz, e apresentamos como se deu a evolução do conceito físico de energia no contexto das máquinas e para além da mecânica. Nesta segunda e última parte, encerraremos a nossa análise apresentando algumas contribuições decisivas de Joule e Kelvin para a formulação correta e moderna do princípio de conservação de energia e, consequentemente, do conceito físico de energia. Em seguida, daremos a nossa sugestão de como abordar esse conceito em sala de aula.

Palavras-chave: Física; Energia; Máquinas e mecânica.

\begin{abstract}
This paper aims to show the essential aspects of the development of the physical concept of energy, in order to subsidize the choice of teachers on the best way to understand and teach this concept, and it is divided into two parts. Firstly, we have shown some contributions by Thomas Young, Johann Bernoulli, Galileo Galilei, René Descartes and Leibniz, and how was the evolution of the physical concept of energy in the context of machines and beyond the mechanics. In the second and final part, we have
\end{abstract}

\footnotetext{
${ }^{+}$The history of evolution of the physical concept of energy as subsidy for the its teaching and learning - part II

* Recebido: setembro de 2014. Aceito: abril de 2015.

${ }^{1}$ E-mail: carvalhaisgomes@yahoo.com.br
} 
finished our analysis presenting some decisive contributions of Joule and Kelvin for the correct and modern formulation of the principle of conservation of energy and, consequently, of the physical concept of energy. Then, we have given our suggestion on how to approach this concept in the classroom.

Keywords: Physics; Dissipation; Heat and energy.

\section{Introdução}

$\mathrm{Na}$ primeira parte deste artigo, vimos que o desenvolvimento do conceito físico de energia está intimamente relacionado com o desenvolvimento do princípio de que há uma constância no meio de mudança. Ou seja, algo sempre fica constante apesar das mudanças do meio. Além disso, mostramos algumas contribuições dos engenheiros politécnicos franceses e de outros pesquisadores de diferentes áreas da física sobre esse tema. Terminamos a primeira parte mencionando a polêmica que teve entre Joule e Mayer sobre quem foi primeiro a encontrar o equivalente mecânico do calor. Nesta segunda e última parte do artigo, mostraremos mais detalhes da controvérsia que ocorreu entre os dois. Em seguida, finalizaremos a nossa análise com Kelvin, por apresentar uma das primeiras formulações corretas e modernas do princípio de conservação de energia e, consequentemente, do conceito físico de energia.

\section{Algumas contribuições de Mayer}

Julius Robert von Mayer (1814-1878) nasceu em Heilbronn, na Alemanha. Por influência do pai, que era farmacêutico, fez o curso de medicina na Universidade de Tübin, formando-se em 1838. Desde criança, queria conhecer a Índia, o meio encontrado foi o de viajar em um navio holandês, para as colônias holandesas, como médico. A viagem ocorreu entre setembro de 1840 e fevereiro de 1841 (LINDSAY, 1973; CANEVA, 1993). Valente (1999, p. 201) nos esclarece que:

É neste navio e junto a ilha de Java que começa, para Mayer, a aventura intelectual da construção de um conceito de 'força'. Se bem que possamos encontrar alguns indícios anteriores que levavam nesta direç̧ão podemos, no entanto, considerar que é a partir da constatação de uma cor diferente do sangue venoso nos trópicos que Mayer começou um verdadeiro trabalho de construção conceptual com uma entrega total. Para termos uma ideia do que acontecia a Mayer basta dizer que ele praticamente não sai do barco durante a estada em Java. Ora Mayer tinha um grande fascínio por estas paragens. Tal facto só é compreensivel se admitirmos que o que lhe estava a acontecer ao nível das ideias era ainda mais forte do que a curiosidade que o levou para aquelas terras. 
Alguns meses depois de retornar dessa viagem, em 16 de junho de 1841, Mayer envia a Johann Christian Poggendorff (1796-1877) o seu primeiro artigo para publicação nos Annalen der Physik und Chemie. Mas ele não foi publicado e nem retornado ao autor, tendo sido encontrado, trinta e seis anos mais tarde, entre os pertences de Poggendorf (CAJORI, 1908). Encontramos uma versão desse texto para a língua inglesa em Lindsay (1973). Seu título em alemão é "Über die quantitative und qualitative bestimmung der kräft" "'Sobre a determinação quantitativa e qualitativa das forças"). Mayer ainda não dispunha de um valor para o equivalente mecânico do calor, que ele apresentará no artigo seguinte, de 1842. Desse modo, as suas considerações sobre esse assunto foram apenas filosóficas e qualitativas. “[...] Mayer precipitou-se na pressa de publicação, talvez por sentir que estas novas ideias eram revolucionárias na nossa visão do mundo" (VALENTE, 1999, p. 216).

Em 1842, após ter melhorado seus conhecimentos físicos, escreveu uma nova versão de seu trabalho, em apenas sete páginas, e o enviou para Liebig, o famoso químico, editor da revista Annalen der Chemie und Pharmacie (LINDSAY, 1973; CANEVA, 1993; CAJORI, 1908; MARTINS, 1984). Dessa vez, o artigo foi aceito com o seguinte título "Bemerkungen über die kräfte der unbelebten natur" (“Observações sobre as forças da natureza inanimada”). Em nossos comentários, utilizaremos a tradução feita para o português por Martins (1984). Mayer começa o artigo afirmando que o seu intuito é tentar encontrar respostas para o que devemos entender por "forças" e como elas se relacionam entre si. No artigo de 1841, Mayer definiu "força" como a causa das mudanças observadas, pois, pela lógica, nenhuma mudança acontece sem uma causa:

[...] Todos os fenômenos baseiam-se no fato de que a matéria, corpos e suas relações uns com os outros estão sujeitas a mudanças. Das leis de raciocínio lógico, assumimos que isso não pode acontecer sem uma causa. Essa causa chamamos de força (MAYER, 1841 apud LINDSAY, 1973, p. 60, tradução nossa).

Nesse texto, ele amplia essa ideia afirmando que:

Forças são causas, e por isso aplica-se totalmente a elas o princípio: Causa aequat effectum. Se a causa c tem o efeito e, então $c=e$ : se e é novamente a causa de um outro efeito $f$, então $e=f$, e assim por diante: $c=e=f \ldots=c$. Em uma corrente de causa e efeitos, como se torna claro pela natureza de uma igualdade, nenhum elo ou parte de um elo pode torna-se nulo. Nós chamaremos esta primeira propriedade de todas as causas de indestrutibilidade (MAYER, 1842 apud MARTINS, 1984, p. 86).

Ajuntando as duas falas de Mayer podemos concluir que caso as "forças" se destruíssem, o mundo material deixaria de existir, pois não haveria mais mudanças. Em seguida, ele dá continuidade à sua argumentação:

Se a causa dada c produzir um efeito e igual a si, então, por isso mesmo, c deixou de existir: c se transformou em e; se após a produção de e, restasse ainda uma parte de 
c ou ela inteira, então esta causa restante deveria ainda corresponder a outro efeito, e assim o efeito [total] de c deixaria em geral de corresponder a e, o que é contrário à suposição de que $c=e$. Assim, como c se torna e, e se torna f, etc., devemos considerar essas grandezas como diferentes formas de manifestação de um mesmo objeto. A capacidade de assumir diferentes formas é a segunda propriedade essencial de todas as causas. Associando as duas propriedades, podemos dizer: Causas são objetos (quantitativamente) indestrutiveis e (qualitativamente) mutáveis (MAYER, 1842 apud MARTINS, 1984, p. 86).

Percebe-se, de antemão, que a definição de "força" de Mayer não corresponde à de Newton, d'Alembert, Leibniz ou Descartes. Mais adiante ele continua dizendo que:

\begin{abstract}
Encontram-se na natureza duas classes separadas de causas, entre as quais não ocorrem interconversões, conforme mostra a experiência. Uma classe é constituída pelas causas que possuem as propriedades de ponderabilidade e impenetrabilidade - as [formas de] matéria; a outra, pelas causas às quais faltam essas últimas propriedades - as forças, também chamadas imponderáveis por essa propriedade negativa indicada. As forças são, portanto: objetos indestrutíveis, mutáveis, imponderáveis (MAYER, 1842 apud MARTINS, 1984, p. 86-87).
\end{abstract}

A informação de Martins (1984, p. 85-86) é a de que Mayer utilizou a palavra alemã "Kraft", cuja tradução, em um texto moderno de física, seria "força". No entanto, para Mayer, a palavra "Kraft" indica algo muito diferente de nosso conceito atual de força, ou do conceito newtoniano. Poderíamos traduzi-la pela palavra "energia", mas isso seria uma violação histórica, pois o termo "energia" só adquiriu um significado preciso, em física, dez anos após a publicação do artigo de Mayer, pela influência de Rankine e Kelvin. Na verdade, na época de Mayer, faltava uma terminologia adequada para exprimir o que ele queria dizer. Assim, ele fez uso de uma palavra aplicada, naquele tempo, de modos diferentes e conflitantes. A palavra "poder", de acordo com Martins (1984), é uma das traduções de "Kraft" indicadas nos dicionários, e teria a vantagem de permitir invocar um significado mais amplo e obscuro, como o que Mayer queria indicar. Vamos verificar alguns exemplos práticos que ele cita sobre o que compreende por força:

Uma causa que realiza o levantamento de uma carga é uma força; seu efeito, a carga erguida, é também igualmente uma força; de modo mais geral pode-se exprimir isso assim: uma distância espacial entre objetos ponderáveis é uma força; como esta força produz a queda dos corpos, chamamo-la de força de queda. Força de queda e queda, e ainda de modo mais geral, força de queda e movimento, são forças que se relacionam como causa e efeito, forças que se transformam uma na outra, duas formas diferentes de manifestação de um mesmo objeto. Por exemplo: uma carga parada no chão não é uma força: ela não é nem causa de um movimento, nem do levantamento de uma outra carga; mas ela se transforma nisto [em uma força] na medida em que é erguida acima do solo; a causa - a distância entre uma carga e a Terra - e o efeito 
- a quantidade do movimento gerado - estão em uma relação de igualdade, como ensina a mecânica (MAYER, 1842 apud MARTINS, 1984, p. 87-88).

Mayer faz uma análise de uma situação muito comum para os estudiosos da conservação da "vis viva", a novidade está nele mostrar que essa conservação é um caso particular de uma lei geral de indestrutibilidade das "forças". Para tanto, ele une grandezas que já eram conhecidas e definidas por diferentes nomes, colocando-as em uma mesma categoria: "forças". Por consequência, no caso que o "movimento" - que é uma "força" na concepção de Mayer desaparece, sem que se ganhe "força de queda" ou se produza outro "movimento", será necessário encontrar qual outra "força" que surgiu. Vejamos como ele expressa esse questionamento:

\begin{abstract}
Em inúmeros casos vemos um movimento cessar, sem que ele tenha produzido um outro movimento, ou um levantamento de um peso; mas uma força que existiu não pode se tornar nula, e sim apenas transformar-se em uma outra forma [de força], e pode-se consequentemente perguntar: que outras formas pode assumir a força que aprendemos a conhecer como força de queda e movimento? Apenas a experiência pode nos fornecer informação sobre isso. Para tornar a experimentação conveniente, devemos selecionar instrumentos que possam produzir realmente uma cessação do movimento e que sejam o mínimo possível alterados pelos objetos pesquisados. Friccionemos por exemplo duas placas metálicas entre si, e observaremos o desaparecimento do movimento, e em contraposição veremos o aparecimento de calor; pergunta-se agora apenas se o movimento é a causa do calor. Para nos assegurarmos dessa relação, devemos esclarecer a questão: nos inúmeros casos em que o calor aparece quando há desaparecimento do movimento, não terá o movimento um outro efeito além da produção de calor, e o calor outra causa além do movimento (MAYER, 1842 apud MARTINS, 1984, p. 89)?
\end{abstract}

Descartando as hipóteses de alterações no estado de agregação e da diminuição de volume dos corpos que se atritam como as causas do surgimento do calor, Mayer também consegue colocá-lo na categoria de um tipo de "força". Ou seja, se não se pode encontrar o surgimento de "[...] qualquer outro efeito do movimento desaparecido, exceto calor; e para o calor que surge, nenhuma outra causa, exceto o movimento; então a partir daí é preferível supor que o calor surge do movimento, do que supor uma causa sem efeito ou um efeito sem causa [...]" (MAYER, 1842 apud MARTINS, 1984, p. 92). Assim, Mayer admite que a "força de queda", o "movimento" e o "calor" "[...] são diferentes formas de uma mesma coisa, mas que essa coisa - a 'força', em abstrato - não é propriamente nenhuma dessas três coisas. Esta é uma concepção muito semelhante ao nosso conceito moderno de energia" (MARTINS, 1984, p. 67). Para Valente (1999, p. 224-225), a pretensão de Mayer é a unificação da natureza, por meio da ligação das diferentes formas com que a "força" aparece. Dessa maneira, o que o movia, realmente, era uma visão unificada da natureza centrada nas ligações entre as diferentes "forças". Estabelecidas essas conexões, Mayer (1842 apud Martins, 1984, 93) pergunta: 
[...] de quão grande seja a quantidade de calor correspondente a uma determinada quantidade de força de queda de movimento. Por exemplo, podemos determinar a que altura devemos erguer um determinado peso acima do solo da Terra para que seu poder de queda seja equivalente ao aquecimento de um igual peso de água de $0^{\circ}$ a $1^{\circ} \mathrm{C}[\ldots]$

Ao contrário do artigo anterior, Mayer (1842 apud Martins, 1984, p. 93-94, grifo nosso) dá uma resposta a essa importante questão com o seguinte raciocínio:

Pela aplicação das leis estabelecidas às relações de calor e volume dos gases encontra-se que o abaixamento do mercúrio que comprime um gás iguala-se à quantidade de calor liberada pela compressão e segue-se daí - sendo o indice de proporcionalidade das capacidades [térmicas] do ar atmosférico sob pressão constante e sob volume constante $=1,421$, que o abaixamento de um peso de uma altura de aproximadamente 365 m corresponde ao aquecimento de um igual peso de água, de $0^{\circ} a 1^{\circ}$. Compara-se com estes resultados as realizações de nossas melhores máquinas a vapor, e ver-se-á que apenas uma parte mediocre do calor aplicado sob a caldeira se transformou realmente em movimento ou erguimento de carga; e isto pode servir como justificação para a procura de outra forma vantajosa de produção de movimento, ao invés do esperdício da diferença química entre $C$ e $O$, a saber: pela transformação da eletricidade, produzida por meio químicos, em movimento.

Mayer foi extremamente conciso em sua resposta, deixando para explicar com mais detalhes a metodologia empregada, para encontrar esses valores, em seu próximo trabalho publicado em 1845. Esse teve que ser publicado por conta própria, sob a forma de um livreto, após ter sido recusado inclusive pela revista Annalen der Chemie und Pharmacie, a mesma que publicou o de 1842 (LINDSAY, 1973; CANEVA, 1993; MARTINS, 1984). O seu título é "Die organische bewegung in ihrem zusammenhang mit dem stoffwechsel, ein beitrag zur Naturkund" ("O movimento orgânico e sua conexão com o metabolismo, uma contribuição para a História Natural”). Novamente recorremos à Lindsay (1973, p. 99-145; 1975, p. 284-307) para termos acesso ao artigo em língua inglesa. Para entendermos melhor o seu raciocínio, vamos fazer uma descrição um pouco mais extensa apenas da parte em que Mayer fornece mais detalhes dos cálculos feitos para encontrar o equivalente mecânico do calor. Ele começa afirmando que para fazer essa demonstração é necessário examinar o comportamento dos fluidos elásticos - gases - com o calor e o efeito mecânico. Desse modo, ele menciona as experiências de GayLussac que provaram, por meio de experimentos, que um fluido elástico ao se expandir no vácuo não sofre alteração de temperatura. Ao contrário do que ocorre quando um gás se expande contra uma pressão em que a temperatura decresce. Sutilmente, Mayer está dizendo que na expansão de um gás há uma relação entre o calor e o efeito mecânico produzido. A seguir, ele fornece alguns exemplos para ilustrar o seu raciocínio: 
Vamos assumir que 1 centímetro cúbico de ar a $O{ }^{\circ} \mathrm{C}$ e uma pressão de 27 polegadas de mercúrio [condições padrão] é aquecido por uma quantidade de calor x a volume constante a $274{ }^{\circ} \mathrm{C}$. Quando for permitido a esse gás se expandir para um espaço evacuado de mesmo volume, ele ainda manterá a temperatura de $274{ }^{\circ} \mathrm{C}$ e o meio circundante dos vasos que contêm o gás durante a experiência de expansão não mudará a temperatura. Agora, porém, considere outro caso em que 1 centímetro cúbico de ar é aquecido de $\mathrm{O}^{\circ} \mathrm{C}$ a $274{ }^{\circ} \mathrm{C}$ não a volume constante, mas a pressão constante (a saber, 27 polegadas de mercúrio). Nesse caso, uma maior quantidade de calor é necessária. Represente isso como $x+y$.

Em ambos os casos acima o ar é aquecido de $0{ }^{\circ} \mathrm{C}$ a $274{ }^{\circ} \mathrm{C}$, e, em ambos os casos, o ar expande de um volume para o dobro do volume.

No primeiro caso, a quantidade de calor requerida foi $x$. No segundo, foi $x+$ y. No primeiro caso, o efeito mecânico produzido foi zero, mas no segundo foi o equivalente para levantar 15 libras de 1 polegada.

Se o ar é esfriado sob as mesmas condições com que foi aquecido, uma quantidade de calor igual à que foi tomada é devolvida. A quantidade de ar dada, se é esfriada de $274{ }^{\circ} \mathrm{C}$ a $\mathrm{O}^{\circ} \mathrm{C}$ sem gasto simultâneo de efeito mecânico (ou com pressão ausente), irá, consequentemente, devolver a quantidade de calor $=x$. No entanto, em esfriamento a pressão constante com gasto de força de queda equivalente ao necessário para levantar 15 libras de 1 polegada, o ar irá devolver a quantidade de calor $x+y$.

O vapor na máquina quando se expande comporta-se como o ar a pressão constante. A quantidade de calor necessária para o aquecimento e expansão do vapor é de $x+y$. No processo de esfriamento o vapor não experimenta nenhuma pressão particular e, portanto, o esfriamento acontece sem (ou com muito pequeno) gasto de efeito mecânico. Ele devolve a quantidade de calor $x$. Portanto, há associado com cada ciclo do pistão no cilindro da máquina uma perda de calor igual a y. Assim, a operação da máquina é inseparavelmente ligada com um consumo de calor.

A quantidade de calor que deve ser gasta para produzir uma determinada quantidade de efeito mecânico deve ser avaliada experimentalmente (MAYER, 1845 apud LINDSAY, 1975, p. 290-291, tradução nossa).

Em resumo, um gás emprega calor para produzir efeito mecânico ao se expandir sob pressão, diminuindo a sua temperatura. Isso explica o motivo da diferença entre o calor empregado para se aquecer um gás a pressão constante e a volume constante. No primeiro caso, parte do calor é utilizada para produzir efeito mecânico e outra parte para aumentar a temperatura do gás. No segundo caso, todo o calor empregado é utilizado apenas para aumentar a temperatura do gás. A diferença entre os dois calores específicos estará, portanto, relacionada com o efeito mecânico produzido. Sendo mais fácil aquecer um gás a volume constante do que a pressão constante. "[...] Se o calor absorvido pelo gás no aquecimento de $\mathrm{t}^{\circ} \mathrm{C}$ a volume constante é $\mathrm{x}$, 
o calor necessário para aquecer o gás no mesmo intervalo de temperatura a pressão constante será $\mathrm{x}+\mathrm{y}$. Se, no último caso, o peso levantado é $\mathrm{P}$, então $\mathrm{y}=\mathrm{Ph}$ " (MAYER, 1845 apud LINDSAY, 1975, p. 291-292, tradução nossa). Após essas considerações, Mayer (1845 apud Lindsay, 1975, p. 292, tradução nossa) mostra como ele fez o cálculo teórico do equivalente mecânico do calor:

Um centímetro cúbico de ar atmosférico a $0{ }^{\circ} \mathrm{C}$ e 0.76 metros de pressão barométrica pesa (tem uma massa de) 0.0013 grama. Se ele é aquecido de $1{ }^{\circ} \mathrm{C}$, o ar se expande em 1/274 parte do seu volume e, ao mesmo tempo, levanta uma coluna de mercúrio de 1 centímetro quadrado de seção transversal e 76 centímetros de altura de 1/274 metro. O peso dessa coluna é 1033 gramas. $O$ calor específico do ar (que da água toma como unidade), a partir do trabalho de Delaroche e Berard, é 0.267. A quantidade de calor que um centímetro cúbico de ar recebe a fim de ir de $0{ }^{\circ} \mathrm{C} \mathrm{a} 1{ }^{\circ} \mathrm{C}$ a pressão constante é, portanto, igual ao calor que $(0.0013)(0.267)=0.000347$ grama de água teria a sua temperatura aumentada de $1{ }^{\circ} \mathrm{C}$. De acordo com Dulong, a quem a maioria dos físicos segue, a quantidade de calor que o ar recebe para aquecer de 1 ${ }^{\circ} \mathrm{C}$ a volume constante está para uma pressão constante na razão de 1:1.421. Se usarmos isso para calcular o calor necessário para aquecer 1 centímetro cúbico de ar de $1{ }^{\circ} \mathrm{C}$ a volume constante como 0.000347/1.421 = 0,000244 [...].

A diferença $(x+y)-x=y$ é, portanto, $0.000347-0.000244=0.000103$ unidades de calor [Mayer usa grau $\left(^{\circ}\right)$ de calor. Na verdade ele está usando calorias equivalentes - Ed. Nota.] Para o gasto disso, 1033 gramas de mercúrio é levantado 1/274 centímetros. Assim, a unidade 1 de calor [1 caloria] é equivalente a 1 grama levantada de 367 metros [ou uma energia de 3,59 joules-Ed. nota.].

Para chegar a esse número, ele utilizou o valor do calor específico do ar, a pressão constante, e o resultado da razão entre os calores específicos a volume constante e a pressão constante, ambos encontrados na época por Gay-Lussac. Segundo Martins (1984, p. 94), a diferença entre o equivalente mecânico do calor obtido - 3,6 J/cal - e o aceito atualmente - 4,186 $\mathrm{J} /$ cal - não é devida a um erro de cálculo ou de princípio, e sim aos dados inexatos utilizados por Mayer, mas os únicos disponíveis na época. Se utilizássemos o mesmo procedimento de cálculo, com os dados numéricos atuais, obteríamos o valor correto. Convém lembrar que os resultados de Gay-Lussac não eram conhecidos por boa parte da comunidade científica de seu tempo. Veremos adiante que um dos motivos dos ataques de Joule a Mayer é devido ao desconhecimento desses valores. Dessa vez, Mayer não poderá ser acusado de falta de clareza em suas afirmações, conforme corrobora Mach (1986, p. 232, tradução nossa):

[...] todas as tentativas para mostrar que as reivindicações de créditos de Mayer são infundadas devem cair ao chão, tendo em vista a clareza concei- 
tual a que ele finalmente alcançou quando deu o valor do equivalente mecânico do calor e claramente declarou, em poucas palavras, o modo que foi calculado. Ele foi o primeiro de todos os físicos a perceber que não há necessidade de novos experimentos para essa determinação, e que geralmente os números conhecidos são suficientes para isso. Ele também foi o primeiro a compreender corretamente a experiência de Gay-Lussac e utilizá-la como base de cálculo.

Esse artigo de 1845 de Mayer é extenso e contém muitas outras informações interessantes, além do cálculo detalhado do equivalente mecânico do calor. Por exemplo, uma espécie de catálogo das formas da "força" conhecidas na época com referência a 25 experimentos que demonstram a metamorfose de uma forma de "força" em outra. As "forças" citadas são: "força de queda"; "força de movimento", que pode ser simples ou vibracional; "calor"; "magnetismo"; "eletricidade"; "força química"; "separação química" e "combinação química". Antes de denominá-las, Mayer afirma que em todos os processos físicos e químicos a "força" envolvida é uma quantidade constante. É nesse artigo, também, que Mayer aborda pela primeira vez a importância de suas observações sobre a cor do sangue nos trópicos que lhe ocorreu naquela viagem de navio de 1840. Ele nos conta que devido a uma infecção inflamatória aguda nos pulmões que atingiu muitos dos marinheiros, quando estavam a noroeste de Java, precisou fazer vários procedimentos de sangria. Foi quando percebeu que o sangue tirado da veia do braço possuía, quase sem exceção, uma cor vermelha brilhante, muito semelhante ao arterial. Ao contrário do que observara na Europa em que o sangue arterial era muito vermelho e o das veias era mais escuro. O fenômeno chamou a sua atenção instigando-o a encontrar a razão do sangue de um europeu em Java ser diferente do mesmo europeu na Europa. De acordo com Martins (1984, p. 64-65):

Mayer conhecia a teoria de Lavoisier a respeito do calor animal. Segundo esta teoria, o aquecimento dos animais é o resultado de um processo de combustão ou oxidação: o sangue arterial conduz a todas as partes do organismo o oxigênio, que reage nos tecidos, produzindo gás carbônico que é transportado pelo sangue venoso até os pulmões. Mayer considerou que a diferença entre a cor do sangue arterial e venoso seria devida à diferença entre seus conteúdos de oxigênio e gás carbônico. Ora, segundo Mayer, para que o corpo humano possa ser mantido a uma temperatura uniforme, o desenvolvimento de calor dentro dele deve manter uma relação quantitativa com o calor perdido pelo corpo - deve depender, portanto, da temperatura do meio ambiente; portanto a produção de calor e o processo de oxidação, assim como a diferença de cor dos dois tipos de sangue, devem ser globalmente menores nas zonas tórridas do que em regiões temperadas.

Resolvido esse problema, ele pôs-se a pensar a respeito da origem e dos efeitos produzidos pelo calor animal. Já se sabia, na época, que a fonte desse calor era o alimento absorvido 
pelo organismo. No entanto, um ser vivo pode produzir calor diretamente pelo seu "calor corporal" e pelo atrito gerado mecanicamente entre os seus órgãos. Segundo Martins (1984, p. 6566, grifo nosso):

[...] Mayer considera que mesmo um organismo vivo é incapaz de gerar calor a partir do nada. Por isto, ele é levado a admitir que o calor total produzido por um ser vivo (isto é, a soma do calor corporal com o calor produzido mecanicamente pelo organismo) deve corresponder ao calor gerado por oxidação dos alimentos naquele ser vivo. Mas, nesse caso, o calor gerado pelos efeitos mecânicos do ser vivo deve ser limitado pela sua capacidade de realizar esforço mecânico, e esta, por sua vez, pelo calor que pode ser gerado pelo alimento. Mayer conclui que o calor produzido mecanicamente pelo organismo deve manter uma relação quantitativa invariável para com o trabalho gasto em sua produção. Mas esse resultado deve ser válido, não só para organismos vivos, mas para qualquer tipo de processo da natureza. Portanto, Mayer conclui que o calor produzido através de uma ação mecânica qualquer é proporcional ao trabalho empregado.

Encontramos em Lindsay (1973), Caneva (1993), Martins (1984), Cajori (1908), Valente $(1993,1999)$ - e outros - a concordância de que todo o processo de construção conceitual do princípio da conservação da energia de Mayer começa com a análise desse fenômeno biológico: a cor do sangue nos países quentes. A partir disso, Mayer dedicou-se a fundamentar as suas ideais e a dar-lhes uma forma convincente. Porém, apesar de seus argumentos serem considerados brilhantes, originais e com potencial interesse, “[...] os seus contemporâneos não deram muita importância às suas teorias por considerarem que os seus trabalhos tinham uma forte componente metafísica [...]" (VALENTE, 1993, p. 83). Isso explica, em parte, a grande dificuldade que ele tinha em publicar os seus artigos. Outro fato considerável é que ele era de fora da academia, faltando-lhe um defensor do meio acadêmico, alguém que tivesse compreendido, corrigido e dado publicidade as suas ideias. Por último, a linguagem que ele utilizava para expressar as suas concepções não era a da física de seu tempo.

\section{Algumas contribuições de Joule}

James Prescott Joule (1818-1889) nasceu em Salford, perto de Manchester, na Inglaterra, em uma rica família que tinha uma indústria de cerveja. Devido ao uma ligeira deformidade espinhal e uma saúde frágil, ele não frequentou a escola, sua educação foi assegurada por tutores. O ensino científico, entre 1834 e 1837, coube a John Dalton (1766-1844), famoso pelo seu trabalho sobre a teoria atômica (CROPPER, 2001; CARDWELL, 1989; KARGON, 2010).

Esta influência de Dalton poderá explicar algumas das diferenças essenciais entre Joule e Mayer e, nomeadamente, no que diz respeito à interpretação do calor. Enquanto este último não especulou sobre a natureza do calor, disso 
não sentindo qualquer necessidade, Joule vai interpretar o calor sensível como a vis viva dos átomos, numa altura em que os átomos ainda não existiam no campo da filosofia natural. Sendo estas duas personalidades muito diferentes e vivendo em locais muito diferentes há alguns paralelismos interessantes no que diz respeito ao desenvolvimento das suas ideias (VALENTE, 1999, p. 300).

Joule não teve educação universitária. Foi um cientista amador, assim como Mayer foi um físico amador. Em 1833, com a aposentadoria do pai por motivos de saúde, assumiu a cervejaria aos 15 anos de idade. Nas horas de folga, fazia experimentos de química e Física em seu laboratório particular (CARDWELL, 1989; KARGON, 2010). Segundo Valente (1999, p. 303):

As suas qualidades de experimentalista desenvolvem-se durante os anos de convivência científica com Dalton e continuarão, depois, a evoluir e a refinarse. O seu campo preferido de estudo (ou de entretenimento, como sugere Cardwell) começou por ser o domínio das experiências com electricidade, o que reflecte o ar dos tempos, pois com Faraday desenvolve-se toda uma euforia eléctrica. Daí o primeiro interesse científico de Joule: motores eléctricos. Veremos, mais adiante, qual a sequência lógica que o levará desse interesse às questões do desenvolvimento da noção de equivalente mecânico do calor. A medida, cada vez mais exacta, deste equivalente será o grande objectivo de toda a sua carreira científica.

Dentro desse contexto de "euforia elétrica", Joule interessou-se, particularmente, pela melhoria da eficiência do motor elétrico. O que pode ser explicado pela ligação de sua família à indústria. Não demorou muito para ele perceber, que a sua pesquisa em busca de um maior desempenho dos motores elétricos teria que envolver também o estudo da produção de calor nos circuitos elétricos. Afinal:

Uma das variáveis associadas ao funcionamento de um motor eletromagnético é o aparecimento de calor. Em todas as máquinas o aparecimento de calor devido ao atrito tinha sido reconhecido por muitos anos como indicando o desperdício de potência, por essa razão, a prática há muito estabelecida de utilizar lubrificantes para reduzir o atrito. $O$ aquecimento elétrico de motores e circuitos associados podem muito bem indicar outra fonte de desperdício. O comportamento prescrito deve ser investigado mesmo que a conexão entre esse calor e um desperdício de potência seja obscura. Se a bateria e o circuito são usados para gerar calor apenas, e nenhum trabalho foi feito, zinco ainda seria consumido na bateria o que seria certamente um desperdício (CARDWELL, 1989, p. 35, tradução nossa). 
No final do ano de 1840, Joule enviou um artigo intitulado "On the production of heat by voltaic electricity" para a Royal Society of London para ser publicado no Philosophical Transactions, um periódico da instituição. A publicação do artigo na íntegra foi recusada, aparecendo no Proceedings of the Royal Society, especializado apenas em resumos. Nesse trabalho, Joule mostrou que o "efeito calorífico" produzido pela passagem da corrente em um fio é proporcional ao quadrado da magnitude da corrente multiplicado pela resistência do fio, qualquer que seja o comprimento, espessura, forma ou tipo de metal. O que é conhecido hoje em dia por "efeito Joule". Ele também deduziu que o calor produzido pela combustão do zinco em oxigênio estava relacionado com a resistência à condução elétrica. "[...] O aquecimento do circuito era, portanto, inevitável e claramente implícito a um desperdício de zinco na bateria. [...]" (CARDWELL, 1989, p. 36, tradução nossa). Após a publicação desse resumo:

[...] ele continuou com seu trabalho prático, embora tenha se tornado menos proeminente. Ele escreveu um pequeno artigo sobre pilhas voltaicas, mas o mais importante de tudo, ele terminou seu trabalho sobre o calor gerado por uma corrente elétrica. Esse trabalho, publicado na Philosophical Magazine \{1841\}, foi muito mais abrangente do que a breve nota na revista Proceedings que fez pouco mais do que apresentar um pedido de prioridade. Dessa vez, ele deu detalhes dos três conjuntos de experimentos em que uma corrente elétrica passou, sucessivamente, por duas bobinas diferentes de fio de cobre, uma bobina de fio de cobre e uma bobina de fio de ferro e, por último, uma bobina de fio de cobre e uma coluna de mercúrio em um tubo de vidro [...] (CARDWELL, 1989, p. 39, tradução nossa).

Em decorrência desses e de outros experimentos, Joule começou a fazer especulações sobre a natureza e a origem do calor. Ele verificou que a oxidação do zinco aquece menos a bateria quando há corrente elétrica, do que a mesma quantidade de zinco dissolvido sem gerar uma corrente. Era como se uma parte do calor desenvolvido na bateria fosse transportada pela corrente para aos fios. Mas, ao analisar a corrente elétrica produzida pela rotação de uma bobina de fio de cobre entre os polos de um imã, ou seja, por uma máquina magneto-elétrica - precursor do dínamo moderno -, sem qualquer ligação com uma bateria, também observa-se o aparecimento de calor nos fios. Joule concluiu, então, que o calor não era transportado de um lugar para outro, e sim criado pela passagem da corrente elétrica (CARDWELL, 1989; VALENTE, 1999).

Esse foi um dos argumentos contra a teoria do calórico. O primeiro trabalho de Joule em que ele começa a utilizar a expressão de convertibilidade entre calor e trabalho e a fazer experimentos quantitativos sobre o valor mecânico do calor data de 1843, um ano depois do primeiro artigo de Mayer sobre esse tema. O seu título é "On the caloric effects of magnetoelectricity and on the mechanical value of heat", sendo publicado no Philosophical Magazine. Martins (1984, p. 70) nos fornece um bom resumo do que se encontra nesse texto: 
[...] O tema básico deste trabalho é o estudo do calor que surge em fenômenos eletromagnéticos. Entre outras coisas, Joule determina experimentalmente que o calor gerado na bobina de um eletroimã é proporcional ao quadrado da corrente elétrica que a percorre - o primeiro estudo quantitativo do efeito Joule. Ele mostra também que em um dínamo ou motor elétrico há uma relação entre o calor produzido pelas correntes elétricas e o trabalho gerado ou consumido. Suas primeiras medidas mostraram que o aquecimento de uma libra de água a $1^{\circ} \mathrm{F}$ era equivalente ao trabalho mecânico capaz de erguer 896 libras à altura de um pé - ou seja, um resultado correspondente a 1 cal $=4,8 \mathrm{~J}$. Em outras medidas descritas no mesmo artigo, os resultados apresentam uma oscilação, entre 3,2 J/cal e 5,5 J/cal. Como observa muito bem Meyerson, resultados tão incertos não eram muito adequados como provas empíricas da existência de uma relação constante entre trabalho e calor.

Em 1845, no mesmo ano em que Mayer edita o seu trabalho mais completo, Joule publica o artigo "On the changes of temperature produced by the rarefaction and condensation of air", na tentativa de melhorar os resultados para o equivalente mecânico do calor. Logo no início do artigo, Joule (1845a, p. 369, tradução nossa, grifo nosso) explica quais são as suas intenções:

[...] Naquele artigo [refere-se ao artigo On the calorific effects of magnetoelectricity, and on the mechanical value of Heat] foi demonstrado, experimentalmente, que a potência mecânica exercida no giro de uma máquina magneto-elécrica é convertida no calor desenvolvido pela passagem das correntes de indução pelas suas bobinas, e, por outro lado, que a potência motriz do motor eletro-magnético é obtida à custa do calor devido às reações químicas da bateria pela qual ele trabalha. Espero, em um período futuro, ser capaz de comunicar alguns novos e muito delicados experimentos, a fim de verificar o equivalente mecânico do calor com a acurácia que a sua importância para a ciência física exige. Meu objetivo atual é relatar uma investigação em que acredito ter conseguido aplicar com sucesso os princípios antes afirmados para as mudanças de temperatura decorrentes da alteração da densidade de corpos gasosos [...].

O que Joule procura é encontrar a experiência mais simples e mais exata para a determinação do equivalente mecânico do calor. Nesse artigo, ele estuda as variações de temperatura produzidas na compressão e dilatação dos gases, estabelecendo que todo o trabalho utilizado na compressão de um gás é convertido em calor. Mas ainda não alcança a precisão desejada. Apesar de melhores do que o artigo anterior, os seus resultados continuam dispersos. Ele mostra também que o ar, ao se dilatar sem realizar trabalho, não sofre variação apreciável de temperatura. "[...] Desconhecia, portanto, os resultados das experiências de Gay-Lussac, que Mayer tão inteligentemente utilizou [...]" (VALENTE, 1999, p. 322). No fim do texto, Joule (1845a, p. 383, tradução nossa, grifo nosso) assim se expressa: 
Crendo que o poder de destruir pertence somente ao Criador, estou inteiramente de acordo com Roget e Faraday na opinião de que qualquer teoria que, quando realizada, requer a aniquilação da força, é necessariamente errada. Os princípios, no entanto, que eu tenho desenvolvido neste artigo estão isentos de tal dificuldade. A partir deles, podemos inferir que o vapor, enquanto expande no cilindro, perde calor em quantidade exatamente proporcional à força mecânica que comunica por meio do pistão; e que, na condensação do vapor, o calor assim convertido em potência não retorna. Supondo nenhuma perda de calor por radiação, etc, a teoria aqui desenvolvida requer que o calor emitido para fora no condensador seja inferior ao que foi comunicado pela caldeira a partir da fornalha, na exata proporção para o equivalente mecânico de potência desenvolvido.

Ainda em 1845, na conferência da British Association, realizada em Cambridge, Joule apresenta uma descrição da famosa experiência de agitação de água por meio de pás. Ele enviou uma carta para a Philosophical Magazine com o título "On the existence of an equivalent relation between heat and the ordinary forms of mechanical power", relatando o que apresentou na conferência. Joule afirma que pretende melhorar o aparato da experiência para obter uma maior precisão, antes de enviar qualquer artigo sobre ela para ser publicado. Apesar de não ter feito nenhum desenho do dispositivo, ele descreve os seus componentes, bem como a metodologia utilizada e os resultados alcançados:

O aparelho exibido antes na Associação consistiu de uma roda de pás de bronze trabalhando horizontalmente em uma lata de água. Movimento pode ser comunicado a essas pás por meio de pesos, polias, etc., $[\ldots]$.

As pás moviam com grande resistência na lata de água, de modo que os pesos (cada um dos quatro libras) desceram a uma taxa lenta de cerca de um pé por segundo. A altura das polias, a partir do chão, tinha doze jardas e, consequentemente, quando os pesos tinham descido ao longo da distância, eles tiveram que ser erguidos novamente, a fim de renovar o movimento das pás. Depois de essa operação ter sido repetida dezesseis vezes, o aumento da temperatura da água foi determinado por meio de um termômetro muito sensível e preciso.

Uma série de nove experiências foi realizada da maneira acima, e nove experimentos foram realizados com vista a eliminar os efeitos de esfriamento ou de aquecimento da atmosfera. Após reduzir o resultado para a capacidade para calor de uma libra de água, verificou-se que para cada grau de calor desenvolvido pelo atrito da água uma potência mecânica igual ao que se pode levantar um peso de $890 \mathrm{lb}$ à altura de um pé tinha sido (JOULE, 1845b, p. 205, tradução nossa). 
Na continuação, ele relembra os valores médios encontrados em suas experiências anteriores, a saber: $823 \mathrm{lb}$ derivada a partir da máquina magneto-elétrica; 795 lb deduzida da rarefação do ar e 774 lb de experimentos, ainda não publicados, sobre o movimento da água em tubos estreitos. Até que dados mais precisos possam ser obtidos, Joule considera que a existência de um equivalente mecânico do calor está provada, assumindo a média de todas essas medidas realizadas, 817 lb, como o valor desse equivalente. Em seguida, faz um comentário:

Quaisquer dos senhores leitores que são tão afortunados por residirem em meio ao cenário romântico do País de Gales ou da Escócia poderiam, não tenho dúvidas, confirmar meus experimentos testando a temperatura da água no topo e no fundo de uma cachoeira. Se o meu ponto de vista está correto, uma queda de 817 pés irá, evidentemente, gerar um grau de calor, e a temperatura do rio Niágara será elevada cerca de um quinto de um grau por sua queda de 160 pés (JOULE, 1845b, p. 206, tradução nossa).

Ampliando o fenômeno observado em laboratório, Joule sugere que em cachoeiras também pode ser verificado a alteração da temperatura da água. Sendo possível, inclusive, estimar a variação dessa temperatura com o auxílio do equivalente mecânico do calor encontrado por ele. Embora o método de agitação da água por meio de pás tenha dado o resultado médio menos preciso, foi o escolhido por Joule para dar prosseguimento em busca de melhores valores por três causas principais: era o mais simples; tinha menos objeções e poderia ser replicado de várias maneiras, bastando substituir a água por outros líquidos (CARDWELL, 1989). No entanto, as pesquisas de Joule não despertaram muito interesse da comunidade científica britânica. Um dos motivos deve-se ao fato de suas experiências não serem "[...] muito simples de ser interpretadas, e os efeitos observados eram muito pequenos - às vezes, apenas centésimos de grau - e variáveis" (MARTINS, 1984, p. 71). Não pertencer ao meio acadêmico, também teve uma influência importante. Cardwell (1989, p. 76, tradução nossa) apresenta outras boas razões:

Joule apresentou o seu trabalho e ideias para as reuniões da Associação Britânica, em 1843, 1844 e 1845 e por meio das páginas da Philosophical Magazine. O mundo científico parecia indiferente. Homens da ciência estavam pensando em outras coisas e os artigos de Joule despertaram pouco interesse. A cruzada magnética estava em curso; Whewell e outros estavam profundamente interessados na teoria das marés; Couch Adams e Leverrier tinham descoberto um novo planeta (Netuno). Não menos intrigante foi a descoberta de Armstrong de que um jato de vapor era eletrificado. O que ele anunciava cientificamente? Estávamos à beira de uma invenção comparável ou de importância ainda maior do que a bateria voltaica ou o motor magneto-elétrico? $O$ que isso significava para o homem prático? Todo mundo estava familiarizado com o imenso poder do vapor; se vapor de alta pressão podia gerar eletricidade diretamente, simplesmente havia novas e excitantes 
perspectivas de fontes de energia revolucionárias e novas aplicações. Faraday se interessava.

A sorte de Joule começou a mudar no ano de 1847, na conferência anual da British Association, realizada em Oxford. Na quinta-feira de 24 de junho, ele se preparou para fazer uma preleção com o título "On the mechanical equivalent of heat, as determined by the heat evolved by the agitation of liquids". Contudo, como era a última palestra do dia, o presidente da sessão solicitou que ele fizesse apenas um breve resumo dos principais pontos do artigo. Ele exibiu e explicou o aparato das pás, fornecendo os resultados alcançados até o momento. Também "[...] fez algumas experiências sobre a compressão de molas de aço. Ele não encontrou nenhum calor gerado; toda a força viva usada para comprimir as molas tinha sido convertida em atração ao longo do espaço. Era, ele acreditava, análogo ao calor latente" (CARDWELL, 1989 , p. 83, tradução nossa). Joule acreditava que novamente as suas ideias passariam despercebidas e a comunicação iria seguir sem comentários, porém:

[...] um jovem levantou-se na sessão e, pelas suas observações inteligentes, criou um vivo interesse na nova teoria. O jovem era William Thomson, que há dois anos passou na Universidade de Cambridge com a maior honra, e agora é, provavelmente, a maior autoridade científica da época [...] (JOULE, 1887, p. 215, tradução nossa).

Em 1893, na inauguração de uma estátua em homenagem a Joule, na cidade de Manchester, William Thomson (1824-1907) - posteriormente conhecido como Lorde Kelvin - relatou esse memorável acontecimento:

Nunca poderei me esquecer da Associação Britânica em Oxford, no ano de 1847, quando em uma das sessões eu ouvi um artigo lido por um jovem, muito modesto, que revelou de modo consciente que ele tinha uma grande ideia a ser desenvolvida. Eu estava tremendamente impressionado com o artigo. A princípio pensei que não poderia ser verdade, porque era diferente da teoria de Carnot, imediatamente após a sua leitura, conversei um pouco com o autor James Joule, esse foi o início de nossos 40 anos de amizade [...] (KELVIN, 1893 apud WATSON, 1947, p. 383-384, tradução nossa).

O apoio de Kelvin foi muito importante na aceitação dos resultados de Joule pelos cientistas ingleses. A partir desse laço de amizade, eles fizeram várias pesquisas em conjunto, culminando em uma série de artigos, incluindo o que tratava sobre os efeitos térmicos de fluidos em movimento, que deu origem a explicação teórica do que hoje é conhecido como "efeito Joule-Thomson" (KARGON, 2010; CARDWELL, 1989). Além do início do reconhecimento, o ano de 1847 também deve ser lembrado como aquele em que Joule descreveu de uma forma mais ampla e coerente o princípio geral de conservação, pois apesar de a preocupação "[...] em generalizar suas ideias, em quase todos os seus artigos Joule estuda apenas problemas bem 
específicos [...]" (MARTINS, 1984, 71). Isso aconteceu em uma palestra popular proferida no St. Ann's Church Reading Room, em 28 de abril de 1847, na cidade de Manchester. Ela foi publicada no Manchester Courie, um jornal local, com o título "On matter, living force, and heat", em maio do mesmo ano (KARGON, 2010; CARDWELL, 1989).

Vamos analisar mais detalhadamente alguns trechos desse texto, pois ele apresenta o embasamento teórico de Joule que o motivou a dar prosseguimento com as experiências sobre o equivalente mecânico do calor. Utilizaremos a reimpressão que está na coletânea "The scientific papers of James Prescott Joule”, publicada pela "The Physical Society of London”, em Londres, no ano de 1884. Desse modo, o ano e as páginas que serão indicadas referem-se a essa fonte. $\mathrm{O}$ autor inicia a sua argumentação afirmando que a impenetrabilidade e a extensão geralmente são interpretadas como propriedades da matéria. Mas deveriam ser reconhecidas como o que a define, pois qualquer coisa que não possua essas duas qualidades não pode ser chamada de matéria. Entre o que considera como propriedades, ele enfatiza a atração gravitacional juntamente com uma:

[...] outra propriedade muito notável apresentada em igual grau por todo o tipo de matéria - sua perseverança em qualquer condição, seja de repouso ou de movimento em que pode ser colocada. Essa faculdade recebeu o nome de inércia, significando passividade, ou a incapacidade de qualquer coisa mudar seu próprio estado. É em consequência dessa propriedade que um corpo em repouso não pode ser colocado em movimento sem a aplicação de certa quantidade de força nele, e também que uma vez que o corpo foi colocado em movimento ele nunca irá parar por si mesmo, mas continuará a se mover para frente, em linha reta, com uma velocidade uniforme, até atuar outra força, a qual, se aplicada contrária à direção do movimento irá retardá-lo, se na mesma direção irá acelerá-lo, e se lateralmente causará o movimento em uma direção curva. No caso em que a força é aplicada na direção contrária, mas em grau igual ao que o colocou em movimento, ele será inteiramente privado de qualquer movimento, pode ter decorrido qualquer tempo desde o primeiro impulso, e o corpo pode ter viajado qualquer distância (JOULE, 1884, p. 266, grifo nosso, tradução nossa).

Na parte grifada, Joule dá a entender que uma força de mesma intensidade que fez um corpo se movimentar é suficiente para colocá-lo em repouso novamente. De fato, de acordo com a mecânica newtoniana, desprezando-se o atrito, isso é verdadeiro. Nesse caso, o mesmo tempo utilizado para tirar o corpo do repouso até atingir uma velocidade v será gasto para fazer o inverso. Ou seja, tem que ter a mesma aceleração em módulo. Mas, na sequência, ele mostra que não era esse raciocínio que tinha em mente. Vejamos:

A partir desses fatos, é óbvio que a força empregada para colocar um corpo em movimento é carregada pelo próprio corpo, ex existe com ele e nele, durante todo o percurso de seu movimento. Essa força possuída 
por corpos em movimento é denominada pelos filósofos mecânicos vis viva ou força viva. O termo pode ser considerado por alguns inadequado, pois, propriamente dito, não há vida, mas é útil, a fim de distinguir a força motriz da que é estacionária na sua natureza, como a força da gravidade. Quando, portanto, nas partes subsequentes desta palestra eu empregar o termo força viva, vocês entenderão que eu simplesmente quero dizer a força dos corpos em movimento. A força viva dos corpos é regulada pelo seu peso e pela velocidade de seu movimento. Vocês entenderão facilmente que se um corpo de certo peso possuem certa quantidade de força viva, duas vezes mais força viva será possuída por um corpo de duas vezes o peso, desde que ambos os corpos se movem com igual velocidade [...] (JOULE, 1884, p. 267, grifo nosso, tradução nossa).

Se o primeiro trecho em destaque não tivesse uma explicação adicional, Joule poderia ser criticado por ainda manifestar a teoria do ímpetus medieval ao falar que a força utilizada para colocar um corpo em movimento permanece com ele durante todo o seu percurso. Justamente quando a teoria de Newton, seu ilustre conterrâneo, já estava consolidada. Entretanto, o que vem depois, mostra que ele se referia à conservação da "vis viva". Talvez essa audácia de interpretar os fenômenos físicos seguindo a ótica da mecânica escalar-analítica-lagrangiana, em vez da mecânica vetorial-newtoniana, no próprio país em que essa última surgiu, tenha contribuído para a dificuldade de aceitação de suas ideias.

Em outras palavras, o que ele afirma é que ao se exercer um esforço físico sobre um corpo gasta-se uma "força”, um "poder" como sugeriu Martins (1984) no caso do Mayer. Essa "força", no entanto, não deixa de existir. Ela é transformada em "força viva" continuando com o corpo enquanto ele estiver se movimentando. Um objeto também possui "força" quando ele está parado, como a força da gravidade - caso contrário, de onde viria a "força viva" de uma pedra solta de uma determinada altura. Ao final da citação, ele declara que a "força viva" depende do "peso" e da velocidade do corpo. Um pouco antes, havia dito "[...] Esta atração dos corpos para a Terra constitui o que é chamado o seu peso ou gravidade, e é sempre exatamente proporcional à quantidade de matéria [...]" (JOULE, 1884, p. 265-266, tradução nossa). Fica claro, então, que ele sabia a diferença entre o "peso" e a "massa", definida por alguns, naquele tempo, como "quantidade de matéria". Desse modo, o mais correto seria dizer que a "força viva" depende da "quantidade de matéria", não do "peso". Quem sabe, por ser uma palestra pública, ele simplificou a ideia para ser melhor compreendido. É mais simples dizer que um objeto é mais pesado do que outro, do que dizer que ele tem mais massa. Depois ele afirma que não há problemas em entender que a "força viva" é diretamente proporcional ao peso, dobrandose esse, dobra-se aquela. Mas:

[...] a lei pela qual a velocidade de um corpo regula a força viva não

é tão óbvia. À primeira vista poderia se imaginar que a força viva seria simplesmente proporcional à velocidade, de modo que se um corpo se 
movesse duas vezes mais rápido que outro, ele teria duas vezes o ímpeto ou força viva. Isso, no entanto, não é o caso, pois se três corpos de igual peso movem-se com as respectivas velocidades de 1, 2 e 3 milhas por hora, as forças vivas serão encontradas proporcionais a esses números multiplicados por eles mesmos, a saber, $1 \times 1,2 \times 2,3 \times 3$, ou 1 , 4 e 9, os quadrados de 1, 2, e 3. Essa lei notável pode ser provada de várias maneiras. Uma bala disparada de uma arma a certa velocidade irá perfurar um bloco de madeira por apenas um quarto da profundidade que seria impelida se a velocidade fosse duas vezes maior. Novamente, se uma bola de canhão encontra-se voando a certa velocidade, quando impelida por uma carga de pólvora dada, e for necessário carregar o canhão de modo a impelir a bola o dobro da velocidade, seria necessário empregar quatro vezes o peso do pó usado anteriormente. Assim, também, um trem que se encontra indo a 70 milhas por hora possui 100 vezes o ímpeto, ou força viva, que ele tem quando viaja a 7 milhas por hora (JOULE, 1884, p. 267, grifo nosso, tradução nossa).

Ao se expressar dessa maneira, percebe-se que ele não quis entrar na polêmica de qual é a verdadeira medida de uma força. Como veremos adiante, um dos seus objetivos é mostrar as várias situações em que a "vis viva" se conserva. Desse modo, a opção foi por evidenciar a relação que existe entre a força exercida sobre um corpo, durante certo espaço percorrido, com o quadrado de sua velocidade. Seguindo o seu raciocínio, ele afirma que um corpo pode ser dotado de "força viva" de várias maneiras. Em uma colisão perfeitamente elástica, por exemplo, um corpo ao colidir com outro de mesmo peso, mas em repouso, transfere a esse a "força viva" que possui permanecendo, após o impacto, parado. Outros modos de transferência de "força viva" acontecem por meio da ação da gravidade ao longo de certa distância e por compressão de uma mola. Ao levantar-se um corpo do chão ou comprimi-lo a uma mola comunica-se ao mesmo uma quantidade de "força viva". Após esses exemplos, Joule (1884, p. 268, grifo nosso, tradução nossa) enuncia a seguinte conclusão:

Vocês logo perceberão que a força viva de que estamos falando é uma das mais importantes qualidades com que a matéria pode ser dotada, e, como tal, seria absurdo supor que ela pode ser destruída, ou mesmo diminuída, sem produzir o equivalente de atração ao longo de uma dada distância da qual estamos falando. Vocês, portanto, se surpreenderão ao saber que, até muito recentemente, a opinião universal tem sido de que a força viva pode ser absolutamente e irremediavelmente destruída por opção de qualquer um. Assim, quando um peso cai para o chão, tem sido geralmente suposto que a sua força viva é absolutamente aniquilada, e que o trabalho que poderia ter sido gasto para elevá-lo até a altura que caiu foi inteiramente jogado fora e desperdiçado, sem a produção de qualquer espécie de efeito permanente. Podemos raciocinar, à priori, que tal destruição absoluta da força viva não acontece, porque é manifestamente absurdo supor que os poderes 
com que Deus dotou a matéria possam ser destruídos ou criados pela ação do homem; mas não ficamos apenas com esse argumento isolado, claro como deve ser a toda mente sem preconceitos. A experiência comum de cada um lhe ensina que a força viva não é destruída pelo atrito ou colisão dos corpos [...].

Até esse ponto, Joule não se distanciou muito de Leibniz na análise da conservação da "vis viva". Mas ao analisar a aparente perda da "força viva" por meio do atrito, a diferença entre os dois torna-se evidente. Conforme nos lembra Iltis (1971, p. 27, tradução nossa):

Leibniz apresenta importantes argumentos matemáticos que $m v^{2}$ e não $m|v|$ era uma medida correta de alguma coisa que se conserva na natureza. Ele, contudo, não apresenta argumentos convincentes de que a sua medida de força também era conservada nas instâncias físicas que ele alegou para isso, com a exceção das colisões elásticas. Em muitos de seus outros argumentos, Leibniz não especifica, adequadamente, um sistema fechado conservativo, já que os mecanismos de transferência de força entre as partes do sistema não são especificados.

Assim como Mayer, e ao contrário de Leibniz, Joule introduziu a conversão da "vis viva" em calor para explicar a sua crença de que não há aniquilamento da "força". Podemos encerrar a nossa análise do artigo com a passagem abaixo, que resume bem a principal mensagem do autor:

A regra geral, então, é que onde quer que a força viva é aparentemente destruída, seja por fricção, percussão, ou qualquer outro meio similar, um equivalente exato de calor é devolvido. O inverso dessa proposição também é verdadeiro, ou seja, que o calor não pode ser reduzido ou absorvido sem a produção de força viva, ou seu equivalente de atração pelo espaço. Assim, por exemplo, na máquina a vapor, verifica-se que a potência é adquirida à custa do calor do fogo, isto é, que o calor provocado pela combustão do carvão é maior, pois há uma parte que não foi utilizada para produzir e manter a força viva da máquina. É certo, porém, observar que isso ainda não tem sido demonstrado pela experiência [...] Todos três, portanto - a saber, calor, força viva e atração pelo espaço (eu também poderia adicionar luz, consistente com o escopo da presente palestra) - são mutuamente conversíveis um no outro. Nessas conversões nada é perdido. A mesma quantidade de calor irá sempre ser convertida na mesma quantidade de força viva. Podemos, portanto, expressar a equivalência em linguagem clara, aplicável em todos os momentos e em todas as circunstâncias. Assim, a atração de $817 \mathrm{lb}$ pelo espaço de um pé é equivalente a, e convertível em, a força viva possuída por um corpo com o mesmo peso de $817 \mathrm{lb}$ quando se desloca com a velocidade de oito pés por segundo, e essa força viva é novamente convertível em quantidade de calor que pode 
aumentar a temperatura de uma libra de água de um grau Fahrenheit [...] (JOULE, 1884, p. 270-271, grifo nosso, tradução nossa).

Não há muita novidade para quem interpretar o que foi escrito sobre o prisma da ciência atual. No entanto, naquele tempo, essas afirmações causaram um estranhamento, inclusive para Kelvin, o maior defensor das ideias de Joule. Kargon (2010, p. 54) nos informa que a primeira referência publicada sobre os trabalhos de Joule apareceu em uma nota de rodapé em um artigo lido por Kelvin na Cambridge Philosophical Society, em junho de 1848. O título do artigo era "On an absolute thermometric scale founded on Carnot's theory of the motive power of heat and calculated from Regnaut's observations". A certa altura, ao comentar sobre a relação existente entre a potência motriz e o calor nas máquinas térmicas, ele afirma que "[...] a conversão de calor (ou calórico) em efeito mecânico é provavelmente impossível, certamente ainda não descoberta. [...]" (THOMSON, 2007a, p. 488). Na nota 4, encontra-se a seguinte explicação:

Essa opinião parece ser quase universalmente seguida por aqueles que têm escrito sobre esse assunto. Uma opinião contrária, entretanto, foi defendida por Mr. Joule, de Manchester; algumas descobertas muito notáveis que ele fez com referência à geração de calor pela fricção de fluidos em movimento e alguns experimentos conhecidos com máquinas eletro-magnéticas parecem indicar uma conversão real de efeito mecânico em calórico. Entretanto, não apresenta evidência de experimento, no qual a operação contrária é exibida, mas deve-se confessar que ainda há muito mistério envolvido em relação a essas questões fundamentais de filosofia natural (THOMSON, 2007a, p. 488).

Mas vimos anteriormente que o apoio de Kelvin às ideias de Joule foi decisivo para o seu reconhecimento científico. Então, como essa relutância de Kelvin em acreditar que é possível converter calor em trabalho foi superada? A resposta a essa pergunta é muito importante, pois a resolução desse impasse foi decisiva para a definição final da conservação da energia na forma que nos é apresentada pelas bibliografias de física do ensino médio ou nas disciplinas de física básica em cursos universitários.

\section{A conservação da energia na forma como a conhecemos}

Kelvin estava inclinado a aceitar a teoria de Sadi Carnot sobre o funcionamento das máquinas térmicas. $\mathrm{O}$ engenheiro francês, ao refletir sobre quais circunstâncias o fluxo de calórico de um corpo quente para um corpo frio daria origem ao máximo rendimento possível nessas máquinas, fez uma comparação com a potência desenvolvida em uma roda hidráulica. Do mesmo modo que em uma roda hidráulica a potência depende da quantidade e da altura da queda d'água, na máquina térmica a potência motriz depende da quantidade de calórico e da diferença entre as temperaturas dos reservatórios térmicos. Nos dois casos, tanta a água quanto 
o calórico se conservam. Contudo, isso entra em contradição com a crença de Joule de que a quantidade de trabalho gerado em um motor térmico corresponde a uma quantidade de calor consumido proporcional ao efeito mecânico produzido. Esse foi o cerne da discordância de Kelvin aos trabalhos de Joule (CROPPER, 2001; THOMPSON, 1910; SMITH, 1977). De acordo com Cropper (2001, p. 81, tradução nossa):

Era a afirmação de Joule da conversão de calor em trabalho, em uma máquina térmica, que incomodava Thomson. Em 1847, Thomson não tinha mais fé na doutrina do calórico, de que o calor era um fluido, mas ele não viu nenhuma razão para descartar outro axioma da teoria do calórico, de que o calor se conserva. Para Thomson, e seus antecessores, incluindo Carnot, isso significava que um sistema, em um determinado estado, tinha uma quantidade fixa de calor. Se o estado for determinado por certo volume $V$ e temperatura $t$, o calor $Q$ contido no sistema é dependente apenas de V e t. Matematicamente, o calor é uma função de estado, o que poderia ser escrito $Q(V, t)$, mostrando a dependência rigorosa das duas variáveis determinantes do estado, Ve t. Para Thomson, em 1847, esse princípio era uma parte essencial da teoria de Carnot, e para negá-lo, teria que derrubar toda a teoria do calor, em que é o princípio fundamental.

Em 1849, no artigo "An account of Carnot's theory of the motive power of heat; with numerical results deduced from Regnault's experiments on steam", Kelvin nos mostra um panorama de suas reflexões sobre esse assunto. Ao fazer um breve resumo da teoria de Carnot, ele utiliza de uma nota de rodapé para formular o seguinte questionamento:

Quando o agente térmico é, desse modo, gasto em condução de calor ao longo de um sólido, o que acontece com o efeito mecânico que ele poderia produzir? Nada pode ser perdido nas operações da natureza - nenhuma energia pode ser destruída. Qual efeito então é produzido no lugar do efeito mecânico que é perdido? Uma teoria perfeita do calor imperativamente exige uma resposta a essa pergunta, ainda nenhuma resposta pode ser dada no estado atual da ciência [...] (THOMSON, 1849, p. 547-548, grifo nosso, tradução nossa).

A sua pergunta não podia ser respondida adequadamente por Joule, pois parte do calor gasto na condução deveria produzir algum efeito mecânico, o que não era observado. Kelvin sinalizava com isso que, para aceitar a conversão de calor em efeito mecânico, precisava entender antes o que acontecia com todo o calor não aproveitado nos fenômenos térmicos. Após intensos debates com outros personagens do meio científico que também se interessavam por esse tema, como Rudolf Julius Emanuel Clausius (1822-1888) e William John Macquorn Rankine (1820-1872), Kelvin se rende à teoria dinâmica do calor (CROPPER, 2001; THOMPSON, 1910; SMITH, 1977). Desse modo, em 1852, em seu artigo "On a universal tendency in nature 
to the dissipation of mechanical energy", ele já trata do "desperdício" de calor como um caso de transformação de energia em processos irreversíveis:

O objetivo da presente comunicação é chamar atenção para uma remarcável conseqüência que se segue da proposição de Carnot, [a saber] que há um absoluto desperdício de energia mecânica disponível ao homem, quando calor é permitido passar de um corpo para outro a temperatura menor, por qualquer meio que não preencha seu [de Carnot] critério de uma máquina termodinâmica perfeita, estabelecido, sob novos fundamentos, na teoria dinâmica do calor. Como é muito certo que só o Poder Criador pode ou trazer à existência ou aniquilar energia mecânica, o desperdício mencionado não pode ser aniquilação, mas deve ser alguma transformação de energia. Para explicar a natureza dessa transformação, é conveniente, em primeiro lugar, dividir os suprimentos de energia mecânica em duas classes - estático e dinâmico. Uma quantidade de pesos a uma altura, prontos para descer e realizar trabalho, quando se desejar, um corpo eletrificado, uma quantidade de combustível contêm suprimentos de energia mecânica do tipo estático. Massas de matéria em movimento, um volume de espaço pelo qual estão passando ondulações da luz ou calor radiante, um corpo que tenha movimentos térmicos entre suas partículas (isto é, não infinitamente frio) contêm suprimentos de energia mecânica do tipo dinâmico (THOMSON, 2007b, p. 491).

Ainda no mesmo artigo, ele começa a utilizar o termo "dissipação de energia" para analisar alguns fenômenos físicos. Por exemplo, ao dizer que quando "[...] calor é difundido por condução, há uma dissipação de energia mecânica e perfeita restauração é impossível" (THOMSON, 2007b, p. 491). O encadeamento dessas reflexões entre a comunidade científica formará a base em que se apoiarão outros pensadores responsáveis pela elaboração do conceito de "entropia" e da "física estatística". Apesar de ser uma história muita empolgante e de grande valor epistemológico, didático e pedagógico, não percorreremos esse caminho, por não contribuir para o principal objetivo de nosso artigo.

Apenas gostaríamos de esclarecer que no ano seguinte da publicação desse artigo de Kelvin, Rankine (1853) propôs uma nova terminologia para as expressões "energia mecânica do tipo estático" e "energia mecânica do tipo dinâmico", chamando-as de "potencial ou latente" e "atual ou sensível", respectivamente. Segundo Coelho (2007, p. 975), Kelvin aceitou o termo "energia potencial", mas junto com Tait publicou em 1862 um artigo em uma revista não científica - Good Words - em que substituiu o termo "energia atual” por "energia cinética".

Para responder a uma possível pergunta do por que pararmos com o estudo do desenvolvimento do princípio da conservação da energia nesse ponto, nos apoiamos em Elkana. Referindo-se ao artigo de Rankine (1853), o autor nos esclarece que nele aparece uma das primei- 
ras formulações corretas e modernas do princípio de conservação da energia, sem fazer, entretanto, qualquer menção a um pesquisador ou trabalho anterior. De acordo com Elkana (1970, p. 59, grifo nosso, tradução nossa):

[...] Rankine era geralmente muito escrupuloso em seus agradecimentos e muito ciente de qualquer tipo de inovação. Como explicar, então, essa omissão? Uma possível explicação é que na mente de Rankine, como nas mentes de Joule, Thomson, Helmholtz e Clausius, esse princípio rapidamente apareceu auto-evidente quanto a teoria dinâmica do calor foi estabelecida na forma final, e as aparentes discrepâncias entre as teorias de Joule e Carnot foram removidas.

Desse modo, podemos encerrar por aqui a nossa análise sobre o desenvolvimento do conceito físico de energia e de seu princípio de conservação. Deve ter ficado claro ao leitor a relação histórica que existe entre esse conceito e o de calor. Em outro trabalho nosso, Gomes (2012), nos concentramos sobre o conceito físico de calor, analisando tanto a sua evolução histórica quanto os estudos realizados sobre as concepções atuais que se tem do mesmo. Fica aqui a sugestão de leitura para quem se interessar.

\section{Considerações finais}

Diante do que apresentamos nas duas partes do artigo, a nosso ver, a melhor definição moderna do conceito físico de energia foi apresentada por Feynman (2005, p. 91, grifo nosso) ao afirmar que:

[...] há certa quantidade, denominada energia, que não muda nas múltiplas modificações pelas quais passa a natureza. Trata-se de uma idéia extremamente abstrata, por ser um princípio matemático; diz que há uma grandeza numérica que não se altera quando algo acontece. Não é a descrição de um mecanismo ou de algo concreto; é apenas um fato estranho de que podemos calcular certo número e, quando terminamos de observar a natureza em suas peripécias e calculamos o número de novo, ele é o mesmo [...].

Concordamos com Poincaré (1968) ao dizer que qualquer que seja a noção do mundo que os experimentos futuros possam nos dar, já sabemos que haverá alguma coisa que permanece constante e que poderemos chamar de energia. Isso é o mais perto possível que podemos nos aproximar de sua definição. Contudo, para que não seja interpretada como uma substância ou fluido contido nos objetos, há que se atentar que ela está associada à configuração de um sistema $^{2}$ e às interações que essa configuração permite. Desse modo, não faz sentido falar em

\footnotetext{
2 Sistema, nesse contexto, deve ser entendido como um "[...] modelo de simplificação, no qual focamos nossa atenção em uma pequena região do universo e desprezamos detalhes sobre o restante do universo fora do sistema
} 
energia de um objeto isolado, além de não ser possível determinar de modo absoluto a energia de um sistema, somente a sua variação. Quando falamos, por exemplo, "a energia potencial gravitacional de uma pedra", cometemos um erro, sob a ótica da ciência. Devido à interação entre a pedra e à Terra - desprezando-se os outros corpos -, a energia está associada ao conjunto formado pelos dois elementos. Essas considerações incluem a energia cinética, conforme Doménech et al. (2003, p. 295, tradução nossa):

Devemos assinalar que as abundantes investigações que temos mencionado sobre as dificuldades dos estudantes em torno do caráter sistêmico da energia, são todas relacionadas com as energias potenciais. Não encontramos, contudo, nenhuma referência a considerações similares relativas à energia cinética: fala-se sistematicamente da energia cinética de um objeto e não se esclarece que essa energia expressa a capacidade do objeto para interagir com os outros porque, precisamente, viaja a uma velocidade determinada em relação a eles. Por consequência, somente podemos falar de a energia cinética de um objeto na medida em que existam outros corpos com os quais possa interagir. Trata-se, definitivamente, de uma propriedade do sistema constituído por esse conjunto de objetos.

Com esses cuidados, podemos evitar reproduzir no universo reificado as três principais ideias associadas à energia no universo consensual, assim resumidas por Pacca e Henrique (2004, p. 160, tradução nossa):

- Energia - causa/fonte: energia como um agente causal, como algo que os corpos possuem que lhes capacitam a realizar alguma ação, produzir mudanças, transformações no ambiente. Assim, o carvão, o Sol, a eletricidade têm energia, pois, por si mesmos, provocam a ação de iluminar, esquentar, movimentar, etc.

- Energia - movimento/ação: a energia torna-se concreta na atividade explícita de um objeto em movimento. Assim, por exemplo, corpos que movem têm energia.

- Energia - substância: a energia é algo que tem existência quase material e pode ser armazenada dentro dos objetos. Assim, por exemplo, quando se fala que a comida e o carvão têm energia armazenada, sugerem-se, muitas vezes, a ideia de uma substância ativa. A própria linguagem frequentemente utilizada em relação à energia - gastar energia, produzir energia, a energia desaparece-sugere a ideia de algo concreto, com existência real como um objeto. Em todas essas ideias,

[...]" (SERWAY; JEWETT JUNIOR, 2005a, p. 180). Assim, um sistema pode ser tanto um corpo ou partícula única, quanto um conjunto de corpos ou de partículas. A fronteira de um sistema, que nem sempre coincide com a sua superfície física, é uma superfície imaginária que divide o sistema de sua vizinhança. 
a energia está incorporada/integrada, de algum modo, a um corpo e, dependendo da situação, pode-se privilegiar uma delas.

Nessa perspectiva, um sistema somente pode variar a energia associada à sua configuração quando passar por um determinado processo de transformações causadas por interações com o meio externo ou por interações entre as suas partes (DOMÉNECH, 2000; DOMÉNECH et al., 2003). No entanto, essas interações não provocam "fluxo de energia", "transferência de energia" ou "transformação de energia". Há apenas transformações do arranjo do sistema envolvido nas interações de tal forma que a energia deve ser calculada, agora, por outras grandezas físicas que pertencem ao sistema e/ou pelas mesmas grandezas com as suas intensidades modificadas. A energia associada a um sistema é apenas uma. Mas, para facilitar o seu cálculo, podemos interpretar as diversas configurações pelas quais passa o sistema e as distintas maneiras pelas quais as interações ocorrem, como se essa energia única estivesse distribuída em diferentes formas (cinética, potencial gravitacional, potencial elástica, elétrica, etc.). Entretanto, deve-se ter claro que:

Falar de distintas formas de energia pode reforçar a sua concepção como algo material que muda de forma. Para evitar isso, devemos associar as diferentes formas de energia (cinética, potencial, gravitacional, etc.) a diferentes configurações dos sistemas e a distintas formas de interagir da matéria. Em outras palavras, a diversidade de adjetivos que normalmente acompanham o termo energia indica-nos a propriedade (ou propriedades) do sistema que intervirá (ou pode intervir) em um determinado processo, ou o tipo de processo que participará o sistema (PINTÓ, 1991; RESNICK; HALLIDAY; KRANE, 1993; ARONS, 1997; KAPER; GOEDHART, 2002). Assim, por exemplo, dizemos que uma bateria tem energia elétrica porque a separação de cargas de sinais diferentes nos polos dota o sistema da capacidade de produzir transformações quando se habilita a possibilidade de circulação de cargas (DOMÉNECH et al., 2003, p. 294-295, tradução nossa).

De acordo com Jewett Junior (2008, p. 211, tradução nossa), na física clássica, é possível variar a energia de um sistema por seis diferentes processos:

W: trabalho feito sobre o sistema por forças externas cujos pontos de aplicação movem-se ao longo dos deslocamentos

Q: energia transferida através do contorno do sistema por calor devido a uma diferença de temperatura entre o sistema e a sua vizinhança

TMT: energia transferida através do contorno do sistema por transferência de matéria (tais como a transferência de um combustível para dentro de um tanque) 
TMW: energia transferida através do contorno de um sistema por ondas mecânicas tais como as ondas sonoras ou ondas sísmicas

TER: energia transferida através do contorno de um sistema por radiação eletromagnética tais como a luz ou micro-ondas.

TET: energia transferida através do contorno de um sistema por transmissão elétrica de uma bateria ou outra fonte elétrica.

Aprovamos essa lista do autor, apenas ressaltamos que a expressão "energia transferida" não deveria ser utilizada no meio acadêmico. Uma sugestão seria dizer simplesmente "variação de energia do sistema”. O importante é que se tenha em mente que a variação de energia em um sistema sempre é acompanhada por uma variação oposta de energia no meio externo em que as interações com o sistema ocorreram. Ou, que a variação de energia de alguma parte do sistema sempre é acompanhada por uma variação oposta em outra parte do mesmo sistema. Isso acontece porque a energia do universo é constante, não podendo ser destruída ou criada. Mas pode ser calculada utilizando várias grandezas Físicas e expressões matemáticas.

Desse modo, podemos " [...] conceber o trabalho como uma forma de intercâmbio de energia. (Entendendo, evidentemente, por variações ou intercâmbios de energia a modificação das configurações das partes do sistema que se interagem) [...]" (DOMÉNECH et al., 2003, p. 297, tradução nossa). Assim como o trabalho (W), o calor (Q) também é um processo pelo qual é possível variar a energia de um sistema. A diferença é que o trabalho (W) envolve interações macroscópicas em que as forças são mensuráveis, ao contrário do calor (Q) que pode ser interpretado como um conjunto de microtrabalhos, realizados em nível microscópico, que ocorrem como consequência do contato entre objetos de diferentes temperaturas ocasionando a variação da energia interna de ambos (DOMÉNECH, 2000; DOMÉNECH et al., 2003). Compreendendo a energia interna como:

[...] a energia associada aos componentes microscópicos de um sistema - átomos e moléculas - quando vistos a partir de um referencial em repouso em relação ao sistema. Inclui a energia cinética e potencial associada com o movimento aleatório translacional, rotacional e vibratório dos átomos ou das moléculas que compõem o sistema, bem como a energia potencial intermolecular (SERWAY; JEWETT JUNIOR, 2005b, p. 589).

A riqueza do debate que vimos ao apresentar a evolução histórica do conceito físico de energia se repete nas discussões sobre as dificuldades de aprendizagem e a melhor maneira de ensiná-la (BEYNON, 1990; DRIVER, 1986; DUIT, 1981, 1987; SEXL, 1981; SOLOMON, 1983, 1992; TEIXEIRA; ASSIS, 2003; VALENTE, 1993, 1999; WARREN, 1982, 1986). Entre as várias propostas presentes na literatura de ensino de ciências, há desde quem defenda iniciar a explicação do conceito de energia como uma espécie de substância "quase-material" que participa em todos os processos que ocorrem a nosso redor (DUIT, 1987), até aqueles que sugerem 
explicar que energia é simplesmente a capacidade de um sistema para realizar trabalho (WARREN, 1982).

A nosso ver, a melhor opção, é a adotada por Doménech (2000) e Doménech et al. (2003), ao associar a noção de energia com a configuração de um sistema e às interações que essa configuração permite. Isso facilita "[...] a compreensão da matéria como formada de um número muito grande de componentes microscópicos, discretos, cuja interação mútua e arranjo espacial resultam nas propriedades e características macroscópicas das diversas substâncias" (VOLCHAN; VIDEIRA, 2001, p. 19). Por consequência, também favorece o entendimento do calor como um processo microscópico de variação da energia interna de um sistema.

\section{Referências}

BEYNON, J. Some myths surrounding energy. Physics Education, v. 25, p. 314-316, 1990.

CANEVA, K. L. Robert Mayer and the conservation of energy. Princeton: Princeton University Press, 1993.

CAJORI, F. The history of the conservation of energy; the age of the earth and sun. Popular Science, v. 73, n. 7, p. 97-111, 1908.

CARDWELL, D. S. L. James Joule: a biography. Manchester: Manchester University Press, 1989.

COELHO, R. L. On the concept of energy: how understanding its history can improve physics teaching. Science \& Education, v. 18, n. 8, p. 961-983, 2007.

CROPPER, W. H. Great physicists: the life and times of leading physicists from Galileo to Hawking. New York: Oxford University Press, 2001.

DOMÉNECH, J. L. L'ensenyament de l'energia en l'edució secundària: anàlisi de les dificultats i una proposta de millora. 2000. 317 f. Tese (Doutorado) - Departament de Didáctica de Les Ciències Experimentals i Socials, Universitat de València, València.

DOMÉNECH, J. L. et al. La enseñanza de la energía: una propuesta de debate para un replanteamiento global. Caderno Brasileiro de Ensino de Física, v. 20, n. 3, p. 285-311, 2003.

DRIVER, R. Teaching energy in schools: towards an analysis of curriculum approaches. In: DRIVER, R.; MILLAR, R. (Eds.). Energy Matters-Proceedings of an Invited Conference: teaching about energy within the secondary school. Leeds: University of Leeds, p. 9-24, 1986.

DUIT, R. Understanding energy as a conserved quantity - remarks on the article by Sexl. European Journal of Science Eduation, v. 3, p. 291-301, 1981. 
. Should energy be illustrated as something quasi-material? International Journal of Science Education, v. 9, n. 2, p. 139-145, 1987.

FEYNMAN, R. P. Física em 12 lições. Tradução: Ivo Korytowski. Rio de Janeiro: Ediouro, 2005.

GOMES, L. C. A ascensão e queda da teoria do calórico. Caderno Brasileiro de Ensino de Física, v. 29, n. 3, p. 1030-1073, 2012.

ILTIS, C. Leibniz and the vis viva controversy. Isis, v. 62, n. 1, p. 21-35, 1971.

JEWETT JUNIOR, J. W. Energy and the confused student IV: a global approach to energy. The Physics Teacher, v. 46, n. 4, p. 210-217, 2008.

JOULE, J. P. On the changes of temperature produced by the rarefaction and condensation of air. Philosophical Magazine and Journal of Science, v. 26, n. 174, p. 369-383, 1845a.

On the existence of an equivalent relation between heat and the ordinary forms of mechanical power. Philosophical Magazine, v. 27, n. 3, p. 205-207, 1845 b.

The scientific papers of James Prescott Joule. London: The Physical Society of London, 1884.

Joint Scientific Papers. Londres: The Physical Society of London, 1887.

KARGON, R. Science in Victorian Manchester: enterprise and expertise. New Jersey: Transaction Publishers, 2010.

LINDSAY, R. B. Julius Robert Mayer: prophet of energy. New York: Pergamon Press, 1973.

. Energy: historical development of the concept. Stroudsburg, Pennsylvania: Halsted Press, 1975.

MACH, E. Principles of the theory of heat: historically and critically elucidated. Dordrecht: D. Reidel Publishing Company, 1986.

MARTINS, R. A. Mayer e a conservação da energia. Cadernos de História e Filosofia da Ciência, v. 6, p. 63-95, 1984.

PACCA, J. L. A.; HENRIQUE, K. F. Dificultades y estrategias para la enseñanza del concepto de energía. Enseñanza de las Ciencias, v. 22, n. 1, p. 159-166, 2004.

POINCARÉ, J. H. La science et l'hypothèse. Paris: Flammarion, 1968.

RANKINE, W. J. M. On the general law of the transformation of energy. Philosophical Magazine, v. 34, p. 106-117, 1853. 
SERWAY, R. A.; JEWETT JUNIOR, J. W. Princípios de Física: Mecânica Clássica. Tradução: André Koch Torres Assis. v. 1. São Paulo: Pioneira Thomson Learning, 2005a.

Princípios de Física: Movimento Ondulatório e Termodinâmica.Tradução: André Koch Torres Assis. v. 2. São Paulo: Pioneira Thomson Learning, 2005 b.

SEXL, R. U. Some observations concerning the teaching of the energy concept. European Journal of Science Education, v. 3, n .3, p. 285-288, 1981.

SMITH, C. W. William Thomson and the creation of thermodynamics: 1840-1855. Archive fo History of Exact Sciences, v. 16, n. 3, p. 231-288, 1977.

SOLOMON, J. Learning about energy: how pupils think in two domains. European Journal of Science Education, v. 5, n. 1, p. 49-59, 1983.

Getting to know about energy in school and society. New York: The Falmer Press, 1992.

TEIXEIRA, O. P. B.; ASSIS, A. Algumas considerações sobre o ensino e a aprendizagem do conceito de energia. Ciência e Educação, v. 9, n. 1, p. 41-52, 2003.

THOMPSON, S. P. The life of William Thomson: Baron Kelvin of Largs. v. 1. London: Macmillan, 1910.

THOMSON, W. An account of Carnot's theory of the motive power of heat; with numerical results deduced from Regnault's experiments on steam. Transactions of the Royal Society of Edinburgh, v. 16, p. 541-585, 1849.

A escala termométrica absoluta baseada na teoria da potência motriz de Carnot e calculada a partir das observações de Regnault. Revista Brasileira de Ensino de Física, v. 29, n. 4, p. 487-490, 2007a.

Sobre uma tendência universal da natureza para a dissipação de energia. Revista Brasileira de Ensino de Física, v. 29, n. 4, p. 491-492, 2007 b.

VALENTE, M. J. P. A pedagogia do conceito de energia: contributo para a utilização formativa do conceito de energia. 1993. 289 f. Dissertação (Mestrado em Ciências da Educação) - Faculdade de Ciências e Tecnologia, Secção de Ciências da Educação, Universidade Nova de Lisboa, Lisboa.

Uma leitura pedagógica da construção histórica do conceito de energia: contributo para uma didáctica crítica. 1999. 603 f. Tese (Doutorado em Ciências da Educação) - Faculdade de Ciências e Tecnologia, Secção de Ciências da Educação, Universidade Nova de Lisboa, Lisboa. 
VOLCHAN, S. B.; VIDEIRA, A. P. Reversibilidade microscópica versus irreversibilidade macroscópica na mecânica estatística clássica. Revista Brasileira de Ensino de Física, v. 23, n. 1, p. 119-132, 2001.

WARREN, J. W. The nature of energy. European Journal of Science Education, v. 4, p. 295 297, 1982.

At what stage should energy be taught? Physics Education, v. 21, n. 3, p. 154-156, 1986.

WATSON, E. C. Joule's only general exposition of the principle of conservation of energy. American Journal of Physics, v. 15, n. 5, p. 383-390, 1947. 